\title{
Percutaneous transluminal coronary angioplasty with cardiopulmonary bypass for stenosis of the most proximal part of the left anterior descending coronary artery
}

\author{
Osamu Ueda, Kyoji Kohchi, Nobuhiko Koga
}

\begin{abstract}
An 85 year old man with unstable angina pectoris was treated successfully with percutaneous transluminal coronary angioplasty supported by cardiopulmonary bypass and intra-aortic balloon pumping. Coronary angiography had shown stenoses in both the left main stem and left anterior descending coronary arteries. Drug treatment had been ineffective and he was too old for coronary arterial bypass grafting.
\end{abstract}

Although percutaneous transluminal coronary angioplasty for stenosis of the left main stem coronary artery without adequate protection of other arteries has been attempted in an emergency and electively, ${ }^{1-3}$ such a lesion is regarded by some as an absolute contraindiction to elective coronary angioplasty. ${ }^{45}$ Vogel and Phillips et al reported using cardiopulmonary bypass for risky coronary angioplasty. ${ }^{67} \mathrm{We}$ report successful emergency angioplasty in a high risk patient who was supported by cardiopulmonary bypass and intra-aortic balloon pumping.

\section{Case report}

An 85 year old man was brought by ambulance to our hospital with chest pain that was refractory to sublingual glyceryl trinitrate. He had a four year history of stable effort angina. On admission, his blood pressure was 152/ $72 \mathrm{~mm} \mathrm{Hg}$, the pulse rate was 66 beats per minute and regular, the lungs were clear, and cardiac auscultation showed no abnormal findings. An electrocardiogram showed sinus rhythm with no clinically significant ST-T change. The attack disappeared after intravenous administration of $5 \mathrm{mg}$ of isosorbide dinitrate. His attacks of angina at rest continued in hospital despite treatment with maximal doses of nitrates and calcium channel blockers. The electrocardiogram during anginal attacks showed slight ST depression in leads V3 to V5. Coronary arteriography on the fifth hospital day showed a severe stenosis $(90 \%$ of the diameter) in the most proximal part of the left anterior descending coronary artery that exten- ded to the left main stem coronary artery and another severe stenosis $(90 \%)$ in the middle left anterior descending coronary artery (fig 1a).

We thought that the patient was too old for coronary arterial bypass grafting. Coronary angioplasty was considered to be so risky that we decided to use cardiopulmonary bypass and intra-aortic balloon pumping during angioplasty. We attempted coronary angioplasty on the sixth hospital day. The patient gave his informed consent. The balloon for intra-aortic balloon pumping was inserted from the right femoral artery. After general anaesthesia with nitrous oxide, the cannulas for cardiopulmonary bypass were introduced into the left femoral artery and the left femoral vein by surgical exposure. Angioplasty was performed via the brachial approach with a $2.5 \mathrm{~mm}$

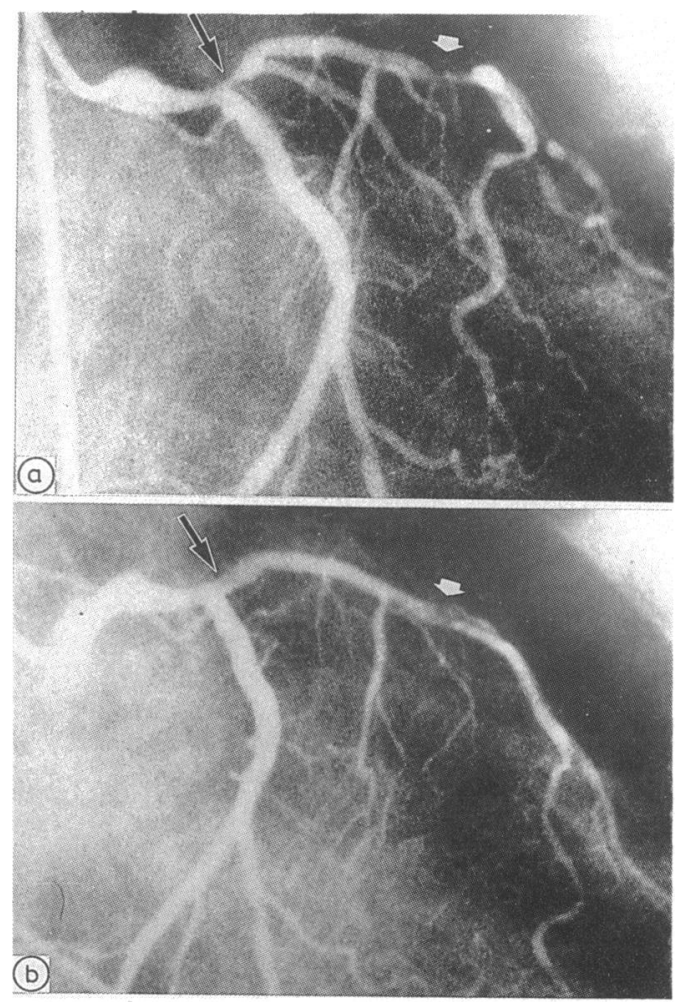

Selective left coronary cineangiograms made (a) before and (b) after percutaneous transluminal coronary angioplasty. The black arrow head and arrow indicate proximal and distal $90^{\circ}{ }^{\circ}$ stenosis respectively; both were successfully treated by angioplasty supported by bypass. 
diameter balloon catheter. When the balloon was across the lesion in the most proximal part of the left anterior descending coronary artery it was inflated three times for 30 to 60 seconds at a pressure of 8 atmospheres. Because the systemic blood pressure fell below $70 \mathrm{~mm} \mathrm{Hg}$ despite intra-aortic balloon pumping during the first inflation, cardiopulmonary bypass was used to give a blood flow of $21 / \mathrm{min}$. Blood pressure was soon restored. The balloon was inflated once for $120 \mathrm{~s}$ at 7 atmospheres when it lay across the lesion in the middle left anterior descending coronary artery. The lesion in the most proximal part of the left anterior descending coronary artery was not sufficiently dilated, so a larger balloon ( $3 \mathrm{~mm}$ diameter) catheter was used and inflated twice for 120 seconds at a maximum pressure of 5 atmospheres.

The diameter of both stenotic regions was increased from $10 \%$ to $50 \%$ by dilatation (fig $1 \mathrm{a}$ and fig 1b). Although there was a minor dissection in the mid left anterior descending coronary artery, there was no occlusion of the artery during the half an hour observation after dilatation. These procedures were performed uneventfully. After angioplasty, angina was completely controlled by medicine and the patient was discharged a month later.

\section{Discussion}

Our patient had two severe stenoses ( $>90 \%$ ) in the left anterior descending coronary artery, and a successful dilatation of only one stenotic region might have relieved the symptoms. To reach the stenosis in the mid left anterior descending coronary artery we had to pass the balloon catheter through the most proximal stenosis. Dilatation of either stenosis was very risky. Because angioplasty of the most proximal lesion required the support of cardiopulmonary bypass and intra-aortic balloon pumping we decided to attempt both stenoses.

We did consider whether the left circumflex coronary artery should have been protected with an additional guide wire, because the most proximal stenosis extended to the left main coronary artery. The stenosis of the left main coronary artery itself was not so severe, however, and we therefore considered that the left circumflex coronary artery was unlikely to become occluded.

We thank Dr H Okazaki, Dr T Baba, Dr H Ohteki, and Professor $T$ Itoh for support and advice.

1 Nakhjavan FK, Goldman AP, Hutt GH. Emergency percutaneous transluminal coronary angioplasty of left main stenosis. Am Heart J 1987;114:643-6.

2 Hartzler GO, Rutherford BD, McConahay DR, Johnson WL, Giorgi LV. "High-risk" percutaneous transluminal coronary angioplasty. Am J Cardiol 1988;61:33G-7G.

3 Stertzer SH, Myler RK, Insel H, Wallsh E, Rossi P. Percutaneous transluminal coronary angioplasty in left main stem coronary stenosis: a five-year appraisal. Int $J$

4 Ryan TJ, Faxon DP, Gunnar RM, et al. Guidelines for percutaneous transluminal coronary angioplasty. Circulatpercutaneous translumin $1988 ; 78: 486-502$.

5 Bourassa MG, Alderman EL, Bertrand M, et al. Report of the joint ISFC/WHO task force on coronary angioplasty.

Circulation 1988;78:780-9.
6 Vogel RA. The Maryland experience: angioplasty and valvuloplasty using percutaneous cardiopulmonary support. Am J Cardiol 1988;62:11K-4K.

7 Phillips SJ, Zeff RH, Kongtahworn C, et al. Percutaneous cardiopulmonary bypass: application and indication for use. Ann Thorac Surg 1989;47:121-3. 